УДК 544.777

\title{
ВЯЗКОСТНЫЕ И ОПТИЧЕСКИЕ ХАРАКТЕРИСТИКИ ЩЕЛОЧНЫХ РАСТВОРОВ Nа-КАРБОКСИМЕТИЛЦЕЛЛЮЛОЗЫ В ОБЛУЧЕННОЙ ЭЛЕКТРОМАГНИТНЫМ ПОЛЕМ ВОДЕ
}

\author{
(C) И.Е. Стась", А.А. Иванов, В.Ю. Чиркова \\ Алтайский государственный университет, пр. Ленина, 61, Барнаул, 656049 \\ (Россия), e-mail: irinastas@gmail.com
}

Установлено, что воздействие низкоинтенсивного (1 Вт) электромагнитного поля ультравысоких частот (175265 МГц) на воду приводит к изменению ее физико-химических свойств. Показано, что значительное увеличение электропроводности и рН воды происходит при определенных частотах поля (180, 210, 220 и 230 МГц) и времени экспозиции -3 ч, что интерпретируется как изменение ее надмолекулярной организации. Установлено существенное снижение относительной вязкости $0,2 \%$ щелочных растворов Na-КМЦ, приготовленных на воде, подвергшейся воздействию электромагнитного поля, в наибольшей степени проявляющееся для частот 210 и 220 МГц. Измерения вязкости проведены в интервале температур $25-40^{\circ} \mathrm{C}$. Эффект сохраняется во всем изученном интервале температур. Из температурной зависимости вязкости рассчитана энергия активации вязкого течения. Установлено ее снижение по сравнению с контрольными образцами. Показано снижение мутности щелочных растворов Na-КМЦ, приготовленных на воде, подвергшейся воздействию электромагнитного поля. Наблюдаемые явления могут быть обусловлены более компактной упаковкой макромолекул полимера вследствие ослабления их гидратации в результате перестройки надмолекулярной структуры воды при облучении.

Ключевые слова: карбоксиметилцеллюлозы натриевая соль, вязкость, энергия активации, мутность, электромагнитное поле, частота.

\section{Введение}

Вода - самый сильный природный растворитель: в воде растворяются в той или иной степени все вещества. В воде набухают и растворяются полимеры, содержащие достаточно большое количество полярных групп, например желатин, агар-агар и др $[1,2]$. Карбоксиметилцеллюлоза (КМЦ) - простой эфир целлюлозы, содержащий карбоксиметильные группы (- $\left.\mathrm{CH}_{2}-\mathrm{COOH}\right)$, также относится к этой группе полимеров [3].

Физико-химические свойства гетерогенных и гомогенных сред определяются не только параметрами компонентов системы, но и их взаимодействием, приводящим к переорганизации системы и процессов, в них протекающих, в том числе к появлению замеряемых откликов на внешнее воздействие [4]. Общей закономерностью поведения большинства таких систем является их низкая устойчивость по отношению даже к слабым внешним воздействиям [5]. Электромагнитное поле (ЭМП) влияет на взаимодействие структурных компонентов воды, водных растворов и дисперсных систем, включающих ассоциаты из молекул одного вида, гидратированные аквакомплексы, коллоидные частицы и другие дискретные образования [6-13]. Следова-

Стась Ирина Евгеньевна - доцент кафедры физической и неорганической химии, кандидат химических наук, e-mail: irinastas@gmail.com

Иванов Алексей Алексеевич - магистрант кафедры физической и неорганической химии, e-mail:mr.alex691@gmail.com

Чиркова Варвара Юрьевна - аспирант кафедры физической и неорганической химии, e-mail: varvara.chirkova@gmail.com тельно, можно ожидать изменения характера сольватационных процессов в облученной воде, который, в свою очередь, и определяет вязкость растворов высокомолекулярных соединений [14].

Большинство исследований по воздействию физических полей на структуру воды и обусловленные ею свойства водных систем посвящены растворам электролитов $[10,11,15,16]$. Мало изу-

\footnotetext{
* Автор, с которым следует вести переписку.
} 
чено изменение свойств водных растворов и дисперсий полимеров природного и искусственного происхождения. Среди подобных исследований можно отметить работу [17], в которой экспериментально обнаружен эффект структурирования воды $\alpha$-аминокислотами и исследовано влияние низкоинтенсивного КВЧизлучения (27-120 ГГц) на процессы структурирования воды и водных растворов аминокислот. В [18] изучено влияние электромагнитного излучения СВЧ-диапазона на формирование надмолекулярных частиц в водных растворах негидролизованного полиакриламида. Установлено, что разогрев образца способствует появлению крупных надмолекулярных частиц.

При получении целевых продуктов с использованием высокомолекулярных веществ, таких как КМЦ и Na-КМЦ, весьма важными характеристиками являются степень и скорость набухания, растворимость и вязкость полученных растворов, которые варьируют введением различных химических добавок, термической и ультразвуковой обработкой. Достижение требуемых технических характеристик путем использования в качестве растворителя облученной низкоинтенсивным полем воды открывает новые возможности при создании технологий переработки растительного сырья и получения целевых продуктов. Варьирование частоты ЭМП и времени экспозиции дает возможность получения продуктов, отличающихся своими свойствами и эксплуатационными характеристиками. Кроме того, исследование растворов ассоциированных жидкостей позволяет расширить представления о природе структурно обусловленных процессов, протекающих в водных системах в результате внешних воздействий.

Цель данного исследования - изучение вязкостных и оптических характеристик щелочных растворов Nа-КМЦ и их изменения при использовании в качестве растворителя воды, подвергшейся воздействию низкоинтенсивного электромагнитного поля различной частоты.

\section{Экспериментальная часть}

В работе использовали низкозамещенную КМЦ (содержание карбоксиметильных групп - 4\%), Исходный полимер очищали $96 \%$ этиловым спиртом, подкисленным до $\mathrm{pH}=5$ уксусной кислотой (90\%), до отрицательной реакции на щелочь по фенолфталеину и на хлорид-ионы с раствором нитрата серебра. Определение количества карбоксиметильных групп проводили с помощью кондуктометрического титрования соляной кислотой [19].

Использованная в работе вода, очищенная с помощью ионитов и обратного осмоса на деионизаторе воды ДВ-301, имела удельную электропроводность $1,8 \cdot 10^{-4} \mathrm{Cm} / \mathrm{M}, \mathrm{pH}=6,3$. Воду хранили в герметически закрытых полиэтиленовых бутылях. Для приготовления 0,2\% растворов Na-КМЦ использовали 1,5 M раствора $\mathrm{NaOH}$ на облученной полем различной частоты воде. В качестве контрольных образцов использовали аналогичные растворы, приготовленные на необлученной воде. В указанные растворы помещали навеску КМЦ и растворяли полимер при перемешивании в течение 3 ч. Выбор концентрации обусловлен малой растворимостью низкозамещенной КМЦ в растворе щелочи.

Относительную вязкость полученных растворов определяли с помощью капиллярного вискозиметра ВПЖ-2 ( $d=1,31$ мм) по отношению времени истечения раствора полимера к времени истечения воды. Время определяли с помощью электронного секундомера с точностью $\pm 0,01 \mathrm{c}$. Число измерений равнялось 10 в каждой из трех серий параллельных экспериментов. Необходимую температуру поддерживали с помощью термостата ТЖ-ТБ-01 (точность поддержания температуры $\pm 0,1^{\circ} \mathrm{C}$ ). Измерения проведены в интервале температур $25-40{ }^{\circ} \mathrm{C}$. Энергию активации вязкого течения жидкости рассчитывали из тангенса угла наклона температурной зависимости вязкости в аррениусовых координатах $\ln \eta-1000 / T$ :

$$
\ln \eta=\ln \beta+\frac{E}{R} \cdot \frac{1000}{T}
$$

где $\eta$ - относительная вязкость; $\beta$ - предэкспоненциальный множитель; $E$ - энергия активации; $R$ - газовая постоянная, $T$ - температура, $\mathrm{K}$.

Мутность $(\tau)$ - коэффициент ослабления света в результате светорассеяния при прохождении луча через слой раствора определенной толщины - рассчитывали по формуле [3]:

$$
\tau=\frac{2,3 D}{l},
$$


где $D$ - оптическая плотность раствора, которую определяли с помощью фотоэлектроколориметра КФК-2 при длине волны $\lambda=400 \mathrm{Hм}, l-$ толщина кюветы $(l=5,0 \mathrm{~cm})$.

Источником электромагнитного поля являлся высокочастотный генератор Г4-119А (Россия), диапазон частот - 175-265 МГц, выходное напряжение - 1-12 В, мощность генератора - 1 Вт. Для облучения воды использовали ячейку емкостного типа. Ячейка состояла из стеклянного стаканчика объемом 50 мл, в центре которого располагался внутренний ВЧ электрод, представлявший собой латунный стержень, изолированный стеклом. Внешним ВЧ электродом служила медная фольга, плотно прилегавшая к внешней поверхности ячейки. Электроды присоединялись к генератору посредством ВЧ кабеля. В ячейку наливали воду, ВЧ кабель ячейки подключали к генератору, на генераторе устанавливали определенное значение частоты и подавали на ВЧ электроды напряжение, равное 12 В. Облучение проводили в течение 30 мин, затем воду переливали в стаканчики для измерения либо электропроводности, либо рН. После измерения воду снова переливали в ВЧ ячейку и продолжали облучение, каждые полчаса измеряя указанные свойства. Измерение электропроводности и рН воды проводили в отдельных экспериментах.

Для определения электропроводности использовали кондуктометр ОК-102/1 с платиновыми электродами. Электроды хранили в дистиллированной воде, периодически очищая поверхность путем промывания разбавленной $\mathrm{HNO}_{3}$. Перед проведением экспериментов проводилась проверка чистоты посуды (ячейки, стаканчика) по величине электропроводности деионизованной воды. Значения рН контролировали с помощью иономера рН-150 М. Электроды: стеклянный и хлорсеребряный. Прибор калибровали с помощью буферных растворов.

При изучении влияния поля на относительную вязкость и оптические свойства растворов Na-КМЦ воду облучали непрерывно полем заданной частоты в течение 3 ч. Эксперименты проводили на следующий день после облучения.

\section{Обсуждение результатов}

Об изменении свойств воды в результате электромагнитной обработки судили по увеличению ее удельной электропроводности и рН. Максимальное увеличение электропроводности наблюдалось в результате воздействия поля частотой 180 МГц и составляло 9,1 \pm 1 раза. Значительное ее возрастание происходило также при частотах 220 и 250 МГц, но было выражено в меньшей степени. Изменение рН составляло максимально 0,45-0,55 единиц, но наблюдалось в результате воздействия поля частотой 210 и 230 МГц. При частотах 180 и 250 МГц увеличение $\mathrm{pH}$ было незначительно. Указанные изменения свойств воды наблюдались при времени воздействия поля, равном 3 ч. После прекращения воздействия свойства воды не возвращались к исходным значениям на протяжении месяца. Неоднозначность частотной зависимости изменения различных свойств воды затруднила выбор частоты ЭМП, поэтому изучение реологических и оптических свойств растворов Nа-КМЦ было проведено при использовании воды, облученной полем различных частот в диапазоне 180-260 МГц. Шаг изменения частоты - 10 МГц.

Изучение вязкостных характеристик водных растворов полимеров весьма информативно, поскольку именно они наиболее чувствительны к изменению молекулярной структуры полимерных матриц полисахаридов и их комплексов [19]. Проведенные исследования показали, что щелочные растворы Nа-КМЦ, приготовленные с использованием облученной воды, имеют меньшую относительную вязкость по сравне-

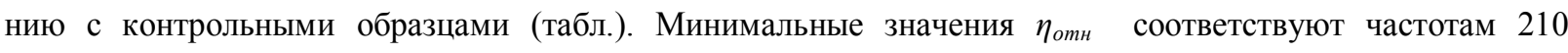
и 220 МГц - ее уменьшение составляет 14-15\% по сравнению с растворами, приготовленными на необлученной воде. Частота 210 МГц соответствует максимальному увеличению рН воды, а частота 220 МГц существенному, но не максимальному увеличению ее электропроводности. При использовании воды, облученной ЭМП других частот, снижение относительной вязкости составило от 2 до 8\%. Для частот 180 , 190, 250 и 260 МГц различий между исследуемыми и контрольными образцами не наблюдалось.

Температурная зависимость относительной вязкости необлученного и облученного ( $\mathrm{f}=210$ МГц) растворов приведена на рисунке 1. Во всем изученном диапазоне температур облученные растворы имеют более низкие значения $\eta_{о т н}$. Однако по мере увеличения температуры различия реологических свойств исследуемых и контрольных образцов снижаются. Так, если при $25{ }^{\circ} \mathrm{C}$ относительная вязкость исследуемого раствора ниже по сравнению с контрольным образцом на $15 \%$, то при $40{ }^{\circ} \mathrm{C}$ лишь на $12 \%$. Аналогичная картина наблюдается и для остальных растворов. Для частоты 240 МГц при $25{ }^{\circ} \mathrm{C}$ относительная вязкость облученного раствора ниже вязкости контрольного образца на $8,8 \%$, а при $40{ }^{\circ} \mathrm{C}-$ на 5,3\% (табл.). 
Относительная вязкость $0,2 \%$ растворов Na-КМЦ, приготовленных на необлученной $(\mathrm{f}=0)$ и облученной электромагнитным полем различных частот (f) воде (время облучения воды 3 ч) при различных температурах

\begin{tabular}{c|c|c|c|c|c|c}
\hline \multirow{2}{*}{$\mathrm{t},{ }^{\circ} \mathrm{C}$} & \multicolumn{5}{|c}{$\eta_{\text {отн }}$} \\
\cline { 2 - 7 } & $\mathrm{f}=0$ & $\mathrm{f}=200 \mathrm{M} Ц$ & $\mathrm{f}=210 \mathrm{M} Ц$ & $\mathrm{f}=220 \mathrm{M} Ц$ & $\mathrm{f}=230 \mathrm{M} Ц ц$ & $\mathrm{f}=240 \mathrm{M} Ц$ \\
\hline 25 & $2,40 \pm 0,13$ & $2,31 \pm 0,14$ & $2,04 \pm 0,10$ & $2,06 \pm 0,11$ & $2,35 \pm 0,14$ & $2,19 \pm 0,13$ \\
30 & $2,24 \pm 0,12$ & $2,13 \pm 0,11$ & $1,92 \pm 0,10$ & $1,92 \pm 0,09$ & $2,20 \pm 0,12$ & $2,07 \pm 0,12$ \\
35 & $2,16 \pm 0,12$ & $2,05 \pm 0,10$ & $1,84 \pm 0,09$ & $1,85 \pm 0,09$ & $2,08 \pm 0,11$ & $2,00 \pm 0,10$ \\
40 & $2,06 \pm 0,10$ & $2,03 \pm 0,09$ & $1,81 \pm 0,09$ & $1,84 \pm 0,09$ & $2,04 \pm 0,10$ & $1,95 \pm 0,10$ \\
\hline
\end{tabular}

Энергия активации вязкого течения определяется величиной межмолекулярного взаимодействия и прочностью структурных образований систем растворов $[2,14]$. Расчеты показали существенное снижение энергии активации вязкого течения щелочных растворов Na-КМЦ, приготовленных на облученной воде (рис. 2). Для растворов, приготовленных на воде, подвергшейся воздействию ЭМП частотой 220 МГц, она оказалась ниже по сравнению с контрольным образцом на 2,44 кДж/моль, т.е. на $30 \%$, а для частоты 210 МГц - на $23 \%$.

Растворы ВМС способны рассеивать свет, что обусловлено большими размерами их молекул [2, 14]. Методом турбидиметрии по данным измерения оптической плотности была рассчитана мутность щелочных растворов Na-КМЦ. Обнаружено заметное снижение их мутности в облученной воде - максимально на $30 \%$ (220 МГц). Причем частоты, соответствующие минимуму относительной вязкости (210 и 220 МГц), соответствуют и минимуму мутности (рис. 3).

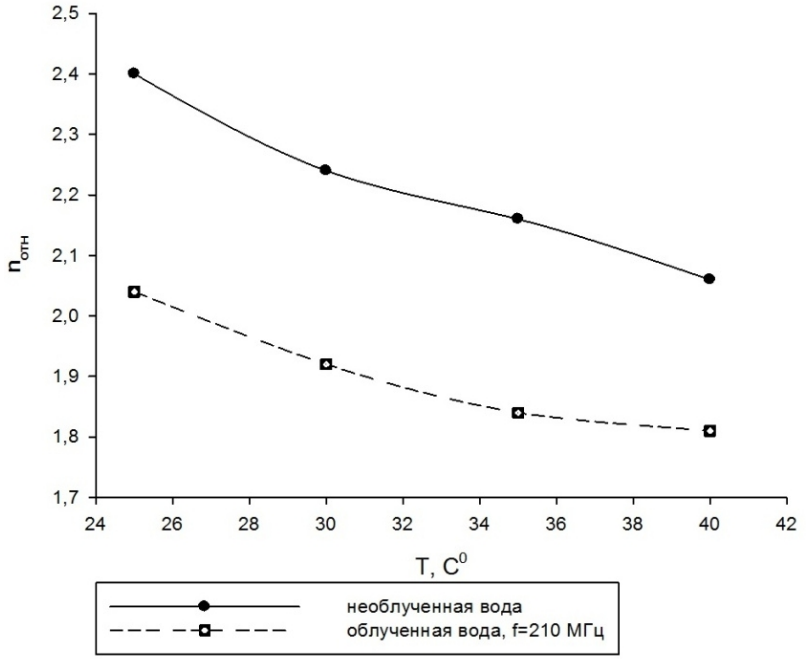

Рис. 1. Зависимость относительной вязкости $0,2 \%$ растворов Na-КМЦ в облученной и необлученной воде от температуры

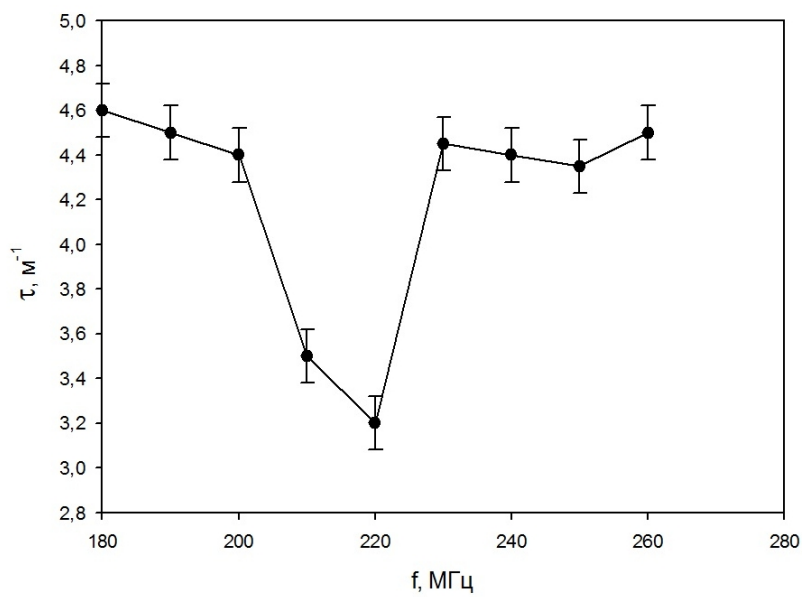

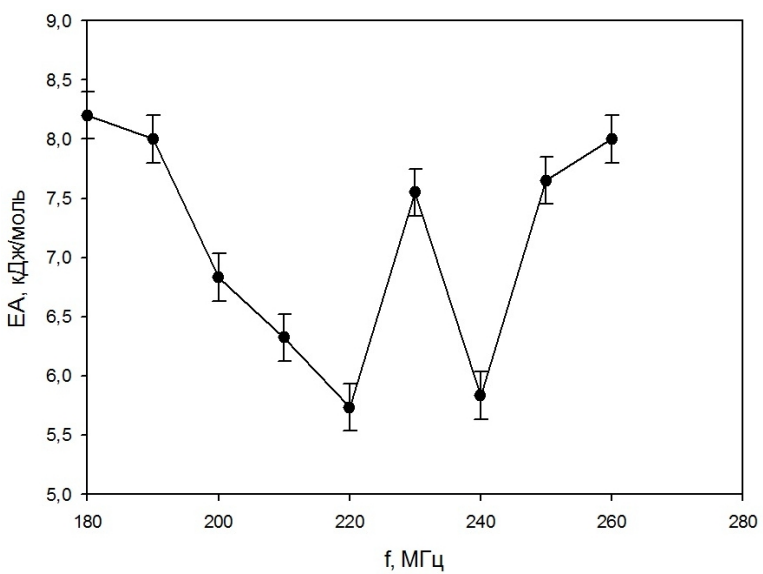

Рис. 2. Энергия активации вязкого течения 0,2\% растворов Na-КМЦ ( $\mathrm{E}_{\mathrm{a}}=8,18$ кДж/моль для контрольного образца)

Рис. 3. Зависимость мутности $0,2 \%$ растворов NaКМЦ от частоты ЭМП $\left(\lambda=400\right.$ нм, $\tau=4,6 \mathrm{~m}^{-1}$ для контрольного образца) 
Благодаря наличию сильнополярных гидроксильных и карбоксильных групп в макромолекуле КМЦ и интенсивному взаимодействию этих групп как внутри, так и между макромолекулами степень асимметрии целлюлозной цепи значительно выше, чем у полимеров, не содержащих сильнополярных групп [2]. Поэтому макромолекула целлюлозы и ее производные относятся к так называемым жесткоцепным полимерам, характеризующимся высокой степенью асимметрии макромолекул. Однако степень асимметрии макромолекул КМЦ не является постоянной и может существенно изменяться в зависимости от различных факторов. В нашем случае таким фактором явилось электромагнитное поле.

Вязкость растворов, содержащих макромолекулы, обычно выше вязкости растворов низкомолекулярных соединений и коллоидных растворов той же концентрации. Только очень разбавленные растворы $\mathrm{BMC}$ можно считать подчиняющимися законам Ньютона и Пуазейля [14]. На форму макромолекул в растворе существенным образом влияет природа растворителя. В одном растворителе молекулы полимеров могут быть более или менее вытянуты, в другом - более свернуты в клубок. Как правило, чем лучше полимер растворяется в данной жидкости, чем более он сольватирован, тем меньше участки молекулярной цепи взаимодействуют друг с другом, тем более вытянуты молекулы и тем выше вязкость раствора. В плохом растворителе макромолекулы мало сольватированы и поэтому образуют более компактные клубки [14]. Кроме того, чем слабее взаимодействие молекул воды с ионогенными группами полимера, тем меньше степень их диссоциации и меньше силы отталкивания между отдельными участками цепи макромолекулы, что также способствует сворачиванию макромолекул в глобулы и изменяет гидродинамические характеристики течения раствора.

Таким образом, установленное снижение относительной вязкости растворов Na-КМЦ свидетельствует о том, что вода, подвергшаяся электромагнитному воздействию, - «плохой» растворитель. Ослабление взаимодействия молекул воды с макромолекулами полимера может быть обусловлено упрочнением межмолекулярных водородных связей и увеличением доли воды, связанной в кластеры, что не противоречит литературным данным [5,6], а также собственным проведенным ранее исследованиям по воздействию ЭМП на свойства растворов электролитов и водных дисперсий $[11,13]$.

Согласно закону Релея при одинаковой массовой концентрации системы и прочих равных условиях рассеяние света определяется размерами и формой частиц. Снижение мутности облученных растворов (уменьшение светорассеяния) свидетельствует об уменьшении размера частиц, что можно также объяснить более компактной упаковкой макромолекул вследствие ослабления их гидратации.

\section{Выводы}

1. Установлено значительное увеличение электропроводности и $\mathrm{pH}$ деионизованной воды в результате воздействия электромагнитного поля в диапазоне частот 175-260 МГц. Степень изменения указанных параметров зависит от частоты и времени полевого воздействия.

2. Установлено снижение относительной вязкости и энергии активации вязкого течения щелочных растворов Nа-КМЦ при использовании облученной воды. Максимальный эффект снижения вязкости соответствует частотам 210 и 220 МГц и составляет 14-15\% при температуре $25{ }^{\circ} \mathrm{C}$. Энергия активации снижается максимально на 30\%. Мутность данных растворов также существенно ниже.

3. Наблюдаемые явления могут быть обусловлены более компактной упаковкой макромолекул полимера вследствие ослабления их гидратации в результате перестройки надмолекулярной структуры воды при облучении.

\section{Список литературь}

1. Папков С.П. Равновесие фаз в системе полимер - растворитель. М., 1981. 272 с.

2. Тагер А.А. Физико-химия полимеров. М., 1968. 314 с.

3. Маркин В.И. Карбоксиметилирование растительного сырья. Барнаул, 2010. 167 с.

4. Зацепина Г.Н. Свойства и структура воды. М., 1974. 168 с.

5. Стехин А.А., Яковлева Г.В. Структурированная вода: Нелинейные эффекты. М., 2008. 320 с.

6. Розин И.Т. Исследование процессов энергоинформационного взаимодействия методами ИК-спектроскопии // Сознание и физическая реальность. 1999. Т. 4, №2. С. 60-64.

7. Саркисов Г.Н. Структурные модели воды // Успехи физических наук. 2006. Т. 176, №8. С. 833-845.

8. Власов В.А. Анализ процессов, обусловливающих влияние магнитного поля на структуру и свойства воды // Науч. журн. КубГАУ. 2012. №81 (07). С. 123-125.

9. Горленко Н.П., Саркисов Ю.С. Низкоэнергетическая активация дисперсных систем. Томск, 2011. 263 с. 
10. Vallée P. Action of pulsed low frequency electromagnetic fields on physicochemical properties of water: Incidence on its biological activity // Journal Europeen d'Hydrologie. 2006. №37 (2). Pp. 221-232.

11. Стась И.Е., Гердт А.П., Аксенова Н.В. Влияние высокочастотного электромагнитного поля на свойства растворов хлоридов щелочных металлов // Известия АлтГУ. 2010. №3(2). С. 141-145.

12. Andreyev Ye.A., Barabash Yu.M., Zabolotny M.A. Dynamics of rheological parameters of water system in lowintensity millimeter wave fields // Proceedings of SPIE - The International Society for Optical Engineering. 1994. №2211. Pp. 518-528.

13. Стась И.Е., Репейкова Л.Ю. Физико-химические закономерности эволюции коллоидных наносистем в жидкой дисперсионной среде под влиянием электромагнитных полей. Барнаул, 2013. 100 с.

14. Воюцкий С.С. Курс коллоидной химии. М., 1976. 512 с.

15. Мокроусов Г.М., Горленко Н.П. Физико-химические процессы в магнитном поле. Томск, 1988. 127 с.

16. Классен В.И. Омагничивание водных систем. М., 1982. 296 с.

17. Синицин Н.И., Ёлкин В.А., Синицина Р.В., Бецкий О.В. Структуризация воды аминокислотами разных классов // Бюллетень медицинских интернет-конференций. 2012. Т. 2, №6. С. 367-374.

18. Федусенко И.В., Кленин В.И., Клохтина Ю.И., Максименко Б.Н., Перовский Э.В. Влияние электромагнитного поля СВЧ диапазона на морфологию водных растворов поливинилового спирта // Известия Саратовского университета. Серия «Химия. Биология. Экология». 2007. Т. 7, №1. С. 48-55.

19. Базарнова Н.Г. Химия древесины и ее основных компонентов : метод. пособие. Барнаул, 2002. $47 \mathrm{c.}$

Поступило в редакиию 13 сентября 2015 г.

После переработки 18 декабря 2015 г. 
Stas I.E. , Ivanov A.A., Chirkova V.Yu. VISCOSITY AND OPTICAL CHARACTERISTICS OF AN ALKALINE SOLUTION OF NA-CARBOXYMETHYLCELLULOSE IN IRRADIATED BY ELECTROMAGNETIC FIELD WATER

Altai State University,Lenina,61,Barnaul,656049 (Russia),e-mail: irinastas@gmail.com

It was established that low intensity exposure $(1 \mathrm{~W})$ ultra-high frequency electromagnetic fields $(175-265 \mathrm{MHz})$ for the water leads to a change in its physical-chemical properties. It has been shown that a significant increase in the electric conductivity and $\mathrm{pH}$ of the water occurs at a certain frequency of the field $(180,210,220$ and $230 \mathrm{MHz})$ and the time of exposure -3 hours, which is interpreted as a change in its supramolecular organization. A substantial reduction in the relative viscosity of a $0,2 \%$ alkaline solution of $\mathrm{CMC}-\mathrm{Na}$, prepared with water having been exposed to electromagnetic, it is most pronounced for the frequencies 210 and $220 \mathrm{MHz}$. The viscosity measurements were carried out in the temperature range $25-40{ }^{\circ} \mathrm{C}$. The effect is maintained throughout the temperature range studied. From the temperature dependence of the viscosity is calculated activation energy of viscous flow. It established its decline compared with control samples. Showed a decrease in turbidity alkaline solutions $\mathrm{Na}-\mathrm{CMC}$, prepared on the water subjected to an electromagnetic field. The observed effects may be due to the more compact packaging of the macromolecules of the polymer due to the weakening of hydration as a result of the restructuring of the supramolecular structure of water under irradiation. frequency.

Keywords: carboxymethyl cellulose sodium salt, viscosity, activation energy, the turbidity of the electromagnetic field,

\section{References}

1. Papkov S.P. Ravnovesie faz v sisteme polimer-rastvoritel'. [Equilibrium phases in the polymer - solvent]. Moscow, 1981, 272 p. (in Russ.).

2. Tager A.A. Fiziko-khimiia polimerov. [Physical chemistry of polymers]. Moscow, 1968, 314 p. (in Russ.).

3. Markin V.I. Karboksimetilirovanie rastitel'nogo syr'ia. [Carboxymethylation vegetable raw materials]. Barnaul, 2010, 167 p. (in Russ.).

4. Zatsepina G.N. Svoistva i struktura vody. [The properties and structure of water]. Moscow, 1974, 168 p. (in Russ.).

5. Stekhin A.A., Iakovleva G.V. Strukturirovannaia voda: Nelineinye effekty. [Structured water: Non-linear effects]. Moscow, 2008, 320 p. (in Russ.).

6. Rozin I.T. Soznanie i fizicheskaia real'nost', 1999, vol. 4, no. 2, pp. 60-64. (in Russ.).

7. Sarkisov G.N. Uspekhi fizicheskikh nauk, 2006, vol. 176, no. 8, pp. 833-845. (in Russ.).

8. Vlasov V.A. Nauchnyi zhurnal KubGAU, 2012, no. 81 (07), pp. 123-125. (in Russ.).

9. Gorlenko N.P., Sarkisov Iu.S. Nizkoenergeticheskaia aktivatsiia dispersnykh sistem. [Low-energy activation of dispersed systems]. Tomsk, 2011, 263 p. (in Russ.).

10. Vallée P. Journal Europeen d'Hydrologie, 2006, no. 37 (2), pp. 221-232.

11. Stas' I.E., Gerdt A.P., Aksenova N.V. Izvestiia AltGU, 2010, no. 3(2), pp. 141-145. (in Russ.).

12. Andreyev Ye.A., Barabash Yu.M., Zabolotny M.A. Proceedings of SPIE - The International Society for Optical Engineering, 1994, no. 2211, pp. 518-528.

13. Stas' I. E., Repeikova L.Iu. Fiziko-khimicheskie zakonomernosti evoliutsii kolloidnykh nanosistem $v$ zhidkoi dispersionnoi srede pod vliianiem elektromagnitnykh polei. [Physical and chemical laws of evolution in nanocolloidal liquid dispersion medium under the influence of electromagnetic fields]. Barnaul, 2013, 100 p. (in Russ.).

14. Voiutskii S.S. Kurs kolloidnoi khimii. [Course of Colloid Chemistry]. Moscow, 1976, 512 p. (in Russ.).

15. Mokrousov G.M., Gorlenko N.P. Fiziko-khimicheskie protsessy v magnitnom pole. [Physical and chemical processes in the magnetic field]. Tomsk, 1988, 127 p. (in Russ.).

16. Klassen V.I. Omagnichivanie vodnykh sistem. [Magnetization of water systems]. Moscow, 1982, 296 p. (in Russ.).

17. Sinitsin N.I., Elkin V.A., Sinitsina R.V., Betskii O.V. Biulleten' meditsinskikh internet-konferentsii, 2012, vol. 2, no. 6, pp. 367-374. (in Russ.).

18. Fedusenko I.V., Klenin V.I., Klokhtina Iu.I., Maksimenko B.N., Perovskii E.V. Izvestiia Saratovskogo universiteta. Seriia «Khimiia. Biologiia. Ekologiia», 2007, vol. 7, no. 1, pp. 48-55. (in Russ.).

19. Bazarnova N.G. Khimiia drevesiny i ee osnovnykh komponentov. Metodicheskoe posobie. [Wood Chemistry and its main components. Toolkit]. Barnaul, 2002, 47 p. (in Russ.).

Received September 13, 2015

Revised December 18, 2015

\footnotetext{
* Corresponding author.
} 
